\title{
ÉTICA DA RESPONSABILIDADE: A PROPOSTA DE HANS JONAS COMO CONTRIBUIÇÃO PARA A EFETIVIDADE DO SISTEMA DE JUSTIÇA
}

\author{
Claudia Maria Barbosa ${ }^{1}$ \\ Maria Cristina Neiva de Carvalho ${ }^{2}$
}

\section{Resumo}

A visão pós-moderna do indivíduo como produtor-consumidor afasta as necessidades tipicamente humanas, muitas vezes essenciais para sua dignidade e sobrevivência. Pessoas e coisas tornam-se meios para o alcance das metas individuais e coletivas focalizadas principalmente no hedonismo. Tal fato pode conduzir o homem para condutas danosas a outro ser humano atual, mas também às gerações futuras, configurando-se, portanto, um cenário que impõe discussões acerca da responsabilidade das ações humanas, inclusive do ponto de vista jurídico. O conceito de responsabilidade jurídica está tradicionalmente vinculado à ideia de imputação, e o funcionamento do sistema judiciário depende da identificação individualizada dos sujeitos (autor e réu) envolvidos no dano, assim como o reconhecimento exato do mesmo, sua extensão, e mensuração dos prejuízos, para os fins de aplicação de pena e cálculo indenizatório. Contudo, a natureza dos desafios que se vem impondo à sociedade em geral e, mais especificamente, a atuação que se exige do Estado, impõe novos mecanismos preventivos, assim como uma punição mais eficaz como forma de tornar a justiça mais efetiva. O princípio responsabilidade de Jonas induz meios de superar tais desafios, em caminho para uma concepção de justiça que seja capaz de identificar, enfrentar, justificar e prevenir danos causados na atualidade.

Palavras-chaves: justiça, sistema de justiça, efetividade; princípio da responsabilidade; ética.

\section{INTRODUÇÃO}

A humanidade vivencia nesse início de terceiro milênio um quadro com ambivalências significativas e preocupantes acerca da existência do homem. Por um lado, a rapidez dos progressos tecnológicos propicia formas variadas de bem-estar, facilidade de comunicação, cura de enfermidades, dentre outros ganhos, mas por outro lado, os instrumentos, as estratégias e a finalidade de tais progressos trazem ameaças à própria sobrevivência humana.

\footnotetext{
${ }^{1}$ Doutora em Direito - UFSC. Pós-doutorado - School of Public Policy and Administration na York University, Canada. Professora titular de Direito Constitucional da Pontifícia Universidade Católica do Paraná - PUCPR. Professora do Programa de Mestrado e Doutorado em Direito da PUCPR. E-mail: claudia.mr.barbosa@gmail.com

${ }^{2}$ Doutora em Direito - PUCPR. Mestre em Psicologia - UFPR. Especialista em Antropologia Cultural - UFPR. Coordenadora e docente da Pós-graduação em Psicologia Jurídica PUCPR. E-mail: cristina.n@pucpr.br vol.09, no. 01, Rio de Janeiro, 2016.pp. 84-99 
Esta problemática tem se configurado como foco de produção científica interdisciplinar, pois apresenta interlocuções principalmente com a educação, filosofia, sociologia, direito, psicologia e ciências da vida. Um exemplo é a obra de Amartya Sem e Bernard Kliksberg (2010), As pessoas em primeiro lugar, que descreve claramente o panorama acerca dos temas que norteiam o funcionamento e entendimento do século XXI.

Os autores abordam o impacto da globalização e suas influências nos arranjos socioeconômicos, que se manifestam na forma como as instituições se relacionam na contemporaneidade, focalizando basicamente a economia de mercado. E assim, a tecnologia pode ser tanto um produto a ser consumido, como um meio de gerar outros produtos, sendo que nessa situação, o liberalismo depende, e muito, do avanço tecnológico, sendo nada mais interessante, portanto que a tecnologia seja globalizada.

Os autores mediante apresentação de inúmeros dados estatísticos relativos à situação de vida em países de diferentes continentes deflagram a inquietante conclusão de que o chamado desenvolvimento global tem ocorrido em ritmo bastante diverso, senão até, em sentido contrário, ao desenvolvimento humano. Isto é, não se tem investido em políticas que vão ao encontro do atendimento dos direitos básicos do homem. A visão do indivíduo como produtor-consumidor afasta as necessidades tipicamente humanas, muitas vezes essenciais para a sua dignidade. Por isso, o alerta dos autores: as pessoas em primeiro lugar!

O reforço desta perspectiva contemporânea que tira o indivíduo, enquanto ser, do centro dos interesses institucionais e relacionais, pode ser também encontrado em obras de Bauman (1998, 2009), quando descreve determinadas características do que ele denominou de "modernidade líquida", tais como a fluidez, superficialidade e efemeridade que permeiam as relações sociais. A busca da satisfação plena faz que o hedonismo seja o caminho do viver do indivíduo e da sociedade contemporânea, e como consequência, as pessoas são meios para o alcance dessas metas individuais e coletivas.

A análise da transformação rápida e radical da sociedade é abordada por Dufour (2008) que não desqualifica os benefícios trazidos pelo liberalismo para o ser humano diante das grandes dificuldades vividas anteriormente a essa era. No entanto, adverte que, se por um lado, essas mudanças fizeram as religiões tradicionais arrefecerem seu poder de condução da vida das pessoas, por outro lado a sociedade pós-moderna segue à outra "divindade", com mandamentos neoliberais, resultantes da moral que rege a lógica de mercado. Essa situação é bem descrita pelo autor em $O$ divino mercado (2008) onde analisa o impacto dessa nova moral em várias facetas das relações humanas: nas instituições educacionais, na política, no sistema legal, dentre outras, o que faz emergir uma nova configuração cultural, a qual exige sérias reflexões sobre o destino a que conduzirá a humanidade.

Uma das características essenciais dessa organização pós-moderna é a disfuncionalidade das instituições normatizadoras da vida em sociedade. Nesse sentido Lebrun (2004) apresenta a discussão das variáveis implicadas em tal panorama incongruente, onde se convive com " a mundialização da economia, a desafetação do 
político, o crescimento do individualismo, a crise do Estado providência, os excessos da tecnologia, o aumento da violência, ao mesmo tempo que a evitação da conflitualidade, a escalada do juridismo..." (LEBRUN, 2004, p.13). Para o autor, na base das crises individuais, institucionais e coletivas que se instalaram na contemporaneidade está o declínio da autoridade em si e da legitimação da mesma, que se expressa na diferença de gerações. O que não significa que a saída seria o retorno ao totalitarismo, retirando o bem precioso do homem - a liberdade - no entanto, deve-se estar alerta para o fato de que a falta de sistemas legisladores legítimos e eficazes, deposita o sujeito numa outra forma de cerceamento, que Lebrun denomina como "mundo sem limite", o qual pode a um tempo tirar quem sabe a própria liberdade de viver, assim como a manutenção da espécie humana.

É justamente nesse aspecto que se apresenta a proposta de Hans Jonas, como recurso teórico que pode subsidiar diversos campos de conhecimento na construção de novos modelos de atuação para o desenvolvimento de uma sociedade justa e sustentável, sendo que para esse fim, o sistema de justiça estatal tem papel fundamental. O autor argumenta que historicamente a ação do homem sobre objetos da natureza não tinha, e parece ainda não ter, aspecto ético significativo, pois a ideia de ética ainda se centraliza essencialmente sobre a relação do homem com seu semelhante, ou seja, trata-se de ética antropocêntrica. Associado a este fato tem-se que a essência do homem, sendo considerada constante, não seria objeto da técnica. Nesse sentido, a preocupação seria com a ação direta, boa ou má, entre as pessoas, considerando o tempo e espaço presentes. Assim, a ética refere-se à intenção do ato praticado aqui-agora, pois os fatos sobre os quais não se tem controle cognitivo seriam obra do acaso.

Contudo, ao analisar a nova configuração sociológica, Hans Jonas constata a insuficiência de modelo ético voltado para o outro imediato, e o considera disfuncional para a atualidade, caracterizada pela amplitude e diversidade das relações humanas, cujas ações têm desdobramentos também bastante amplos e, muitas vezes distantes no tempo e no espaço, do autor original. Em outras palavras, a contemporaneidade exige mecanismos sociais, dentre eles a elaboração e aplicação de legislação, que contemplem a regulamentação do agir humano também em termos prospectivos. Obviamente isto não significa que os valores tradicionais tenham se tornado inválidos para situações imediatas, mas demonstram ser restritos para o "crescente domínio do fazer coletivo" (JONAS, 2006, p. 39) o que impõe, segundo o autor, uma nova perspectiva da ética: a da responsabilidade.

O declínio das fronteiras entre Estado e Natureza, a transformação do homem como sendo também objeto da Técnica (ex: prolongamento da vida, manipulação genética, controle químico de comportamento), impele o surgimento de muitas leis na pós-modernidade para tentar ampliar o controle do homem sobre fatos por ele mesmo produzidos. Tem-se assim, um terreno fértil para a judicialização de fatos até então inéditos para os órgãos judiciários. Segundo Hans Jonas " questões que nunca foram antes objeto de legislação ingressam no circuito das leis que a "cidade" global tem de formular, para que possa existir um mundo para as próximas gerações de homens" (JONAS, 2006, p. 44). 
Parece claro, portanto, que discutir o papel e o impacto dos avanços tecnológicos perpassa necessariamente por discussões sobre a dignidade e a sobrevivência da espécie humana. A partir daí insere-se o questionamento sobre a justiça em tempos de sociedade pós-moderna. O que é justo para o desenvolvimento da sociedade e do homem? O que pode ser ou não permitido para garantir o desenvolvimento econômico? E a sustentabilidade da espécie humana está fundamentada em que bases de justiça? São questões que se impõem para análise da incongruência de uma sociedade que evolui ao preço da progressiva violação de direitos.

Como consequência, tem se observado a ampliação da discussão sobre a ideia de justiça num campo transdisciplinar, onde conhecimentos do direito, psicologia, filosofia e ciências sociais se entrelaçam na tarefa da sustentabilidade da vida humana. Neste contexto a proposta de Hans Jonas sobre uma ética fundamentada no princípio da responsabilidade pode trazer uma importante contribuição para o estudo e aplicação do Direito como ferramenta de controle e transformação social, na configuração da sociedade pós-moderna.

\section{REFLEXÕES SOBRE O PRINCÍPIO RESPONSABILIDADE DE HANS JONAS}

Se o homem contemporâneo assume para si muito do que era projetado sobre inúmeras formas de crenças religiosas ou sobre a própria natureza, deve também assumir a responsabilidade sobre as consequências de suas atitudes em prol da sobrevivência da espécie. A questão das decisões acerca da utilização dos recursos do planeta de maneira prospectiva se impõe e, a esse fato se une o panorama das características da civilização tecnológica. Além disso, como abordado anteriormente, se as instituições responsáveis pela socialização dos indivíduos encontram-se em crise, configura-se a necessidade de se propor uma ética que atenda a esse panorama da contemporaneidade. É nesse contexto que emerge a proposta de Hans Jonas. Como afirmam Battestin e Ghiggi (2010, p. 72):

Jonas quer chamar a atenção para a insuficiência dos imperativos éticos tradicionais diante das "novas" dimensões do agir coletivo. A ética tradicional já não tem categorias consensualmente convincentes para sustentar um debate sobre a ação humana com o meio em que estamos vivendo. No entanto, é central considerar a emergência de uma ética que garanta a existência humana e de todas as formas de vida existentes na biosfera. Jonas propõe o Princípio Responsabilidade, como sendo um princípio ético para a civilização tecnológica.

Como lembram os autores, faz-se necessário construir, através da educação, uma ética com base no imperativo da existência, que é a primeira condição ética responsável para o futuro do mundo. Mediante a construção de conhecimento integrado que permita o movimento de diálogo na busca de princípios éticos responsáveis que permeiem as práticas singulares e coletivas, seria possível colaborar com norteadores socialmente responsáveis para a conduta do homem (BATTESTIN E GHIGGI, 2010, p. 84).

Nesse aspecto, a teoria de Hans Jonas apresenta conotação política essencial, o que é afirmado por Alencastro e Heeman (s/d, p. 4): 
Num horizonte em que até mesmo as ações bem-intencionadas podem resultar em consequências dramáticas para seus destinatários, proposições como as de Jonas buscam uma orientação moral para a ação humana e pretendem articular coerentemente a ética e a política. São formulações preciosas, pois abordam sistematicamente uma questão que não tem sido tradicionalmente trabalhada pelos filósofos da moral, ou seja, a conduta humana diante dos imensos desafios trazidos pela tecnologia e pela ciência moderna.

As decisões políticas tomadas com base numa ética que siga o princípio da responsabilidade focalizarão a possibilidade de um desenvolvimento sustentável e para isso devem priorizar as diferenças das classes sociais, principalmente os desfavorecidos economicamente, a preocupação com as novas gerações da humanidade e com as questões do ecossistema das quais somos totalmente dependentes. Pressupõe-se manter a inovação tecnológica, a qual não se pode mais evitar, mas com cunho antecipatório e responsável (WALDMANN e ELIAS, 2012).

Nesta mesma direção abre-se a proposta de um Judiciário Socioambiental, como aquele que refuta a associação direta entre crescimento econômico e desenvolvimento, e deve buscar a sustentabilidade social, como condição para a sobrevivência e a convivência do ser humano (BARBOSA, 2008).

A proposta de Jonas, contudo, é criticada, entre outros, por Glück (2006), que assinala o fato de que sua proposição teórica de ética se fundamenta em um Estado ativo e com poder, pressupondo que a política pode ser implementada de acordo com uma ética determinada. Contudo, alerta o autor para o fato de que se configura uma fase da sociedade onde, em muitas nações vislumbra-se o enfraquecimento do Estado, ao invés de seu empoderamento, o que comprometeria as premissas de Jonas. Como se para Jonas, o que fosse projetado para o futuro pudesse ser, de alguma forma planejado. Nesse sentido, este autor reconhece que os fundamentos em teorias biológicas são bastante consistentes na proposta de Jonas, mas denuncia a insuficiência de aportes nas ciências sociais, para melhor explicar a ação e natureza humana (GLUCK,2006, p. 41-54)

Para amplificar essa afirmação acerca das bases naturais e sociais da ética, o recente artigo de Sganzerla (2013) "Biologização do ser moral em Hans Jonas" esclarece que embora este autor se utilize de fundamentos das ciências biológicas para a sua proposta de ética, não a identifica como uma moral naturalista. Entende-se que a ética é uma questão ontológica e que o ser em si depende das trocas com o meio que o circunda, portanto parece que as bases sociais da natureza humana estão naturalmente implicadas com os fundamentos biológicos.

Finalmente, para se aproximar a ética de Hans Jonas do campo jurídico, recorre-se ao trabalho de Momo (2010) que aponta o paradoxo que se vive na pós-modernidade, quando o progresso tecnológico intensivo convive com a piora de condições de vida. Momo aponta à concordância entre Hans Jonas e Hannah Arendt de que o homem se inebria diante de sua condição de conhecer e criar, não se apercebendo de suas impotências no que se refere às possibilidades de prever. A esse fato, insere a heurística do medo, proposta por Jonas, como uma alternativa de contornar tal dificuldade humana: 
O princípio de uma contenção responsável - a ideia de um freio nas ações humanas - face à
imprevisibilidade dos efeitos num futuro distante será corroborado através do que Jonas
propõe como a heurística do medo, ou seja, diante da impossibilidade de prevermos todos
os efeitos dos avanços tecnológicos e, até mesmo diante da impossibilidade de prevermos o
que realmente proteger agora, no presente, deve-se ter uma postura que - de certa forma -
antecipe as 'ameaças' (MOMO, 2010, p.134)

Para esse autor, a questão da responsabilidade, embora presente direta ou indiretamente nas reflexões mais tradicionais sobre a ética, nunca tratou do aspecto do dever, o que ficou mais sob a égide do campo jurídico como imputação causal. Mas, o autor explicita que para Hans Jonas:

A responsabilidade não se refere às consequências de uma determinada ação, mas ao próprio objeto pelo qual se é responsável. Isso quer dizer que o poder tem um dever responsável diante do que the foi confiado; pois, possuindo um direito nato, o ameaçado ou o dependente do poder causal do sujeito comanda a ação (MOMO, 2010, p. 135)

Esse fato tem implicação direta no campo jurídico. O sistema jurídico fundamenta-se na ideia de que o agente que com sua ação ou omissão provoca um resultado danoso, tem em regra o dever de repará-lo sendo, portanto necessário o nexo de causalidade entre a conduta do indivíduo e o resultado provocado. A culpa ou intenção do agente que causou o dano é também fator importante para delinear o tipo de responsabilização e a reparação, que são distintas, por exemplo, nas esferas penal, administrativa ou civil, conforme se observem neste caso a responsabilidade subjetiva, objetiva ou, mais modernamente, a responsabilidade pelo risco causado por ação ou omissão do agente (Artigo 927 e seu Parágrafo Único, Código Civil Brasileiro, 2002).

A atual arquitetura do sistema de responsabilidade jurídica está, pois, centrada no indivíduo, na sua conduta e na relação de causalidade existente entre a conduta lesiva e o resultado danoso provocado. É um sistema insuficiente e ineficaz para reparar o tipo de dano a que estão expostas as sociedades contemporâneas, nas quais a conduta que se deve reparar, assim como os danos causados não obedecem à lógica "moderna" do indivíduo que, agindo em desacordo com a lei, dá causa a um dano claro, identificável e mensurável, capaz de ensejar uma reparação social e/ ou juridicamente justa.

Os danos atuais, de diferentes espécies, como os danos ambientais que ameaçam a vida da espécie humana, os decorrentes da manipulação genética, aqueles que são consequência do domínio de tecnologias da informação (redes sociais, internet, sistemas de informação e automação), entre outros, apresentam-se de forma distinta: muitas vezes não são provocados por indivíduo ou um grupo identificado de indivíduos; o nexo de causalidade entre a ação ou omissão e o dano é de difícil comprovação; a prova material e identidade do sujeito não são encontradas; o resultado não é totalmente conhecido ou previsível; as vítimas não são identificáveis ou individualizadas; a reparação "justa" por vezes não é possível porque, dada a natureza e extensão do dano, ele jamais poderia ter ocorrido. 
Na tentativa de superar esses descompassos, algumas áreas do direito, especialmente o direito ambiental, têm desenvolvido categorias e mecanismos jurídicos próprios, a fim de tornar mais eficaz o bem jurídico protegido, mas o caminho nessa direção ainda é bastante longo.

Momo (2010, p. 138) propõe nesse contexto que se aborde aqui o conceito de justiça, apontando que o modelo moral e jurídico clássico não se mostra compatível e suficiente para atender às demandas atuais, exigindo reformulações nesses conceitos para que haja adequação à complexidade da sociedade pós-moderna.

Outra novidade importante neste cenário é que nas sociedades contemporâneas as atitudes dizem respeito também a sujeitos que ainda estão por vir, e consequentemente pelos direitos dos mesmos, que deveriam ser promovidos e respeitados mediante a forma como se conduz as decisões sobre a vida da sociedade. Nesse sentido a heurística do medo proposta por Hans Jonas e discutida no artigo de Barros (2012, p.60) aponta que:

Para Hans Jonas, observar isso nos antecipa em uma responsabilidade peculiar, que advém da causalidade unilateral que temos em relação à humanidade que virá. Trabalhamos aqui com direitos que antecipamos como existentes, ou seja, o de dar aos próximos homens o direito a uma existência nos moldes que consideramos valiosos. Contudo, é sempre preciso lembrar que esse dever é dependente do dever anterior, o de garantir a existência futura dever este que nos traz o direito de procriarmos sem que precisemos ser solicitados a isso, por parte de nossos descendentes.

A inadequação de modelos éticos baseados na imputação causal de atos originários de indivíduos que coexistem no mesmo espaço e tempo, também é explorada por Oliveira (2012, p.388), que identifica o modelo de Hans Jonas centrado não no que é feito em termos de ação moral e sim no que será alvo de atitudes dos sujeitos. Tal modelo refere-se à responsabilização pelo vir a ser e trata-se, portanto, de obrigação por fazer ou deixar de fazer a respeito de situações que extrapolam a objetividade espaço-temporal atual, configurando-se como um alcance cósmico dos atos.

Sendo assim, a inexistência da reciprocidade numa ética para a contemporaneidade conduz à questão do poder e dever ser, sendo que o autor aponta que para Jonas não haveria distinção nesse sentido, pois o dever seria a tomada de consciência do que se pode, fato explicitado na conclusão de Oliveira (2012, p. 415) quando afirma "o que o homem entende como dever já é o seu poder ser. A lei já está inscrita em cada ser e, no caso humano, ela se apresenta como um dever moral".

Apesar de a revolução tecnológica promover profundas transformações no agir humano, das quais não se pode fugir, Santos (2011, p.36) afirma que a pretensão de Jonas é apontar a permanência da possibilidade de se instaurar um "princípio de precaução e preservação como marco reguladores das ações humanas". Para esse autor, a ideia não é a exclusão da ética tradicional, mas sim a ampliação da mesma, recorrendo a diálogos interdisciplinares dada a complexidade da questão.

A partir das exposições até aqui apresentadas referentes a vários autores que defendem a relevância e coesão da teoria de Hans Jonas, assim como a alguns posicionamentos que analisam aspectos da mesma, 
entendidos como frágeis, serão focalizados a seguir alguns pontos da obra de sua autoria "O princípio responsabilidade", que se acredita terem uma relação importante com a possibilidade de integração entre esse modelo e o sistema de justiça.

Hans Jonas (2006, p. 32) afirma que " a violação da natureza e a civilização do homem andam de mãos dadas". Acrescentar-se-ia para fins do objeto da presente discussão, que a essa dupla violação - da natureza e civilização do homem - também dá as mãos a violação de direitos. Mesmo para a ética tradicional, lembra o autor, a inteligência do homem para promover as modificações necessárias - ou que se fazem necessárias? (Grifo nosso) - para a vida em sociedade, deve vir atrelada à moralidade, o que determina um agir condicionado a essa dimensão intra-humana (JONAS, 2006, p. 34).

$\mathrm{Na}$ abordagem tradicional da ética, e sob a qual o sistema de justiça permanece assentado, os fatos são analisados na perspectiva do "aqui-agora" em termos de suas consequências. Como coloca Jonas (2006, p. 37) "ninguém é julgado responsável pelos efeitos involuntários posteriores de um ato bem-intencionado, bem refletido e bem-executado".

O crescimento do poder do homem sobre tudo que o cerca, ocorrido a partir do progresso tecnológico, faz com que preceitos como justiça, misericórdia, honradez, embora continuem válidos, não sejam suficientes na fundamentação da atitude ética diante da complexidade do impacto das ações do homem sobre a sociedade em geral.

O redimensionamento das consequências do agir humano conduz ao fato de que a responsabilidade seja uma faceta imprescindível na ética contemporânea (JONAS, 2006, p. 39). Segundo o autor, na medida em que o poder se incrementa, assim como a impossibilidade de se prever totalmente o impacto do mesmo, torna essencial a aceitação de nossa ignorância sobre a previsão do futuro, o que gera novos entendimentos sobre os sistemas de direitos e deveres, assim como a ética que os subsidia.

A própria tecnologia adquire um significado ético diferenciado uma vez que passa a ocupar subjetivamente um lugar central na finalidade da vida humana. No processamento implicado no progresso tecnológico e ao sucesso por ele buscado da manutenção de um sistema onde "saber tecnologia" implica em sucesso e em poder, mantém-se uma dinâmica onde o fim em si é o progresso, que gera a tecnologia a ser consumida, a se tornar obsoleta rapidamente para que o mercado gire ... Nessa dinâmica o ser, o homem, com suas valências, é quase que descartado.

Embora o homem seja o autor e ator desse processo, para Hans Jonas não se pode mais considerar o homem singular nessa dinâmica sociológica, mas sim o ator coletivo de atos coletivos, onde a produção se entrelaça à ação. Para o autor, esse fato leva à necessidade de que “ a moralidade deve invadir a esfera do produzir, 
da qual ela se mantinha afastada anteriormente, e deve fazê-lo na forma de política pública" (JONAS, 2006, p. 44).

Dessa forma a nova abordagem da ação humana acaba implicando também a natureza da política.

Deflagra-se, portanto uma reflexão de que novos conceitos éticos estão implicados - ou deveriam estar na proposição e implementação de políticas públicas para que direitos não sejam violados, não só agora, mas também numa perspectiva de futuro.

Aqui num certo sentido poderia se identificar aproximação dessa proposição com a apontada por Ulrich Bech (2011), quando na extensão de sua obra Sociedade de Risco: rumo a uma outra modernidade denota a presença e o papel do risco calculado na sociedade atual, fruto da necessidade de controle de variáveis para maior produtividade e consequente crescimento de mercado mas, que por outro lado convive com limitações da percepção de risco, ou seja, do não controle total sobre as consequências do progresso da sociedade.

Entende-se, portanto a importância ainda maior da presença de modelo ético que sustente as decisões da atividade humana relevando a dependência humana da natureza e da sustentabilidade social obtida pela promoção de direitos humanos.

\section{O MUNDO CONTEMPORÂNEO E O SISTEMA DE JUSTIÇA: A NECESSIDADE DE UM NOVO MODELO ÉTICO}

Desde os primórdios da filosofia a "justiça" é um assunto inquietante, dada sua importância para a viabilidade da vida humana, uma vez que sem a sua presença as relações entre os indivíduos são ameaçadas por outros valores que podem colocar em risco até mesmo necessidades básicas para a sobrevivência do homem. Com o poder e representação social que valores religiosos exerceram sobre a sociedade durante séculos, a "justiça" teve quase que invariavelmente um espaço garantido na fisiologia social. Além disso, o avanço histórico do direito como campo de conhecimento e de atuação, que tem seus fundamentos essenciais na busca da justiça, determinou um caráter técnico-científico a esse valor fundamental na vida humana.

Obras recentes como as de Sandel (2011) Justiça - O que é fazer a coisa certa, e de Sen (2011) A ideia de justiça, assim como Filosofia Política Contemporânea, de Will Kymlicka (2006) demonstram a inquietude de pesquisadores atuais sobre o tema, quando em seus trabalhos remontam descritivamente às ideias primevas de justiça, desde a antiguidade, apontando a necessidade de se repensar o tema na contemporaneidade para que haja melhoria na justiça e remoção das injustiças.

A formação do conceito de justiça a partir de fundamentos das ciências cognitivas é abordada no estudo de Carvalho e Candiotto (2013, p. 529) onde concluem que:

A percepção que o sujeito tem de justiça é resultante da articulação de uma rede de estruturas, na qual se inclui o substrato biológico que, a partir das relações como o meio social, constrói representações dos fatos da realidade. Essa relação se estabelece de maneira 
circular, segundo a análise de Francisco Varela, e retrata a visão do paradigma da complexidade defendido por Edgar Morin, o que pode ser um subsídio para as ciências jurídicas e para sujeitos que buscam o sistema de justiça encontrarem novas estratégias para enfrentamento da judicialização da vida.

É antiga a preocupação da filosofia, psicologia e ciências sociais com relação aos processos individuais e coletivos que propiciam o desenvolvimento da moral e da ética e, como consequência da ideia de justiça. A discussão sobre o que é justo se impõe, portanto nesse mundo contemporâneo sem limites, sem pais, sem autoridades religiosas, políticas, educacionais, que são as vias pelas quais o ser humano assimila valores e normas fundamentais para a vida em sociedade.

Certamente sendo bastante simplista, uma vez que não é este o objetivo do presente trabalho, sabe-se que os processos de socialização perpetrados inicialmente pela família, depois pelas instituições educacionais e estendidas por outras instituições públicas e privadas, são fundamentais para o "agir humano" na sociedade. Um estudioso contemporâneo do desenvolvimento da ética e da moral, Yves de La Taille clarifica e importância do ensinamento das virtudes para a formação da moral: "as virtudes morais não somente participam da gênese da moralidade, como representam traços de caráter essenciais à coesão da personalidade moral" (LA TAILLE, 2000, p.109).

Evidencia-se, portanto o papel da educação nesse processo, que originalmente se fundamentava na presença de "autoridades" educacionais formais e informais promotoras da construção de valores individuais e coletivos. No entanto na pós-modernidade deflagra-se relevante crise das autoridades tradicionais, a partir de novas configurações da subjetividade humana e das relações sociais, como exposto por Navas (2009, p. 20):

Tradicionalmente, la escuela tenía como objetivo socializar a los niños en unos valores bien asentados mediante instrucción y disciplina. Pero la modernidad ha ido socavando la tradición y, por otro lado, algunos valores necesarios para compactar la sociedad han dejado también de tener vigencia. Entre ellos, la disciplina y la autoridade (grifo nosso). Las posibilidades de vida son más complejas y están cada vez más abiertas, y la autoridad ya no vale como criterio para educar".

Ainda segundo esse autor, tal panorama, acrescido ao impacto do avanço tecnológico, traz como consequência a necessidade de que a problemática da formação moral seja assimilada e revista pela administração pública em geral e pelas políticas de educação em particular, pois ao não assumir tal responsabilidade tem-se como consequência a manutenção da convivência com o mal-estar social e ineficiências da atualidade (NAVAS, 2009, p. 21).

Acredita-se que a falta de internalização de limites e a metamorfose das formas de disciplinamento pelas quais passa a sociedade - pode-se dizer assim, pois se atende a outros "disciplinamentos" como a lógica de mercado - parece ser variável relevante na busca de instrumentos e representantes externos de normatização social. 
Deflagra-se a partir daí uma busca incessante da sociedade ao Poder Judiciário, a qual tem se ampliado em progressão assustadora. Acumulam-se processos de várias áreas do direito com temáticas repetitivas, ao mesmo tempo em que o mesmo sujeito retorna ao judiciário inúmeras vezes pela mesma causa. Como consequência assiste-se esse sistema se debatendo com a forma de atender tamanha solicitação de prestação jurisdicional de maneira efetiva.

Além das graves carências e má distribuição de recursos institucionais no Brasil, é possível observar esforços dos três poderes governamentais para a legislação e promoção de políticas que objetivem sanar as demandas relativas a conflitos e direitos violados. No entanto, ainda se tem um panorama no país, onde predomina a insatisfação do usuário do sistema de justiça, adicionada ao incremento das consequências sociais quando direitos são violados constantemente.

Como resultado, a procura pela eficácia e celeridade do sistema de justiça tem sido frequente alvo de pesquisas em instituições acadêmicas, assim como o projeto "Limites e possibilidades da eficácia da prestação jurisdicional no Brasil”’, com a intenção de identificar variáveis que obstaculizam a disponibilização de um sistema de justiça mais célere e eficaz.

Da mesma forma tem-se observado recentemente a explosão de projetos de lei relacionados a temáticas que, em outros tempos eram objeto de intervenções de outras instituições que não judiciárias ${ }^{4}$. Isto é, a resposta do Estado tem sido a proposição de novas leis para garantir os direitos, para provocar a remissão das consequências funestas do domínio da economia de mercado, e para promover a paz e justiça. A proliferação de leis, contudo, por si só não garante a efetividade da justiça. Muito ao contrário, a transferência da responsabilidade sobre a solução de conflitos para o Judiciário acaba muitas vezes por tornar o jurisdicionado mais inerte e apático, comprometendo a própria ideia de liberdade que só se realiza na autonomia.

A esse fenômeno denomina-se aqui de judicialização da vida, no qual estudos como o de Brito (2012) apontam esse movimento de uso do judiciário para inúmeras questões de natureza diversas associadas a algumas das características da pós-modernidade: pressa, hedonismo, superficialidade, volatilidade das relações, dentre outras. Como resposta a essa demanda, o Estado responde com o mesmo ingrediente: novas leis, que não se efetivam, que geram sentimentos de impunidade, que deflagram novas violações de direitos.

\footnotetext{
${ }^{3}$ BARBOSA, Claudia Maria (coord.) Projeto Conjunto de Cooperação de Pesquisa: Limites e possibilidades da eficácia da prestação jurisdicional no Brasil. Diretoria de Programas e Bolsas no País - Coordenação-Geral de Programas EstratégicosCoordenação de Indução e Inovação. Edital No 020/2010/CAPES/CNJ.

${ }^{4}$ Como exemplo pode-se citar a Lei 13.010 (aprovada em 26/06/2014) chamada "Lei da palmada" que "Altera a Lei no 8.069, de 13 de julho de 1990 (Estatuto da Criança e do Adolescente), para estabelecer o direito da criança e do adolescente de serem educados e cuidados sem o uso de castigos físicos ou de tratamento cruel ou degradante, e altera a Lei no 9.394, de 20 de dezembro de 1996". As questões relativas à educação de crianças tradicionalmente foram objeto das ciências humanas e da saúde além de já se contar com o Estatuto da Criança e do Adolescente e o Código Penal que, se devidamente implementados, não possibilitariam ocorrências que agora seriam alvo dessa nova legislação.
} 
Há algo a ser interpretado nesse movimento, e a proposta de Jonas é capaz de ampliar olhares e permitir novos e diferentes pontos de vista. O quadro em que se encontra o sistema de justiça brasileiro não parece ser determinado somente e necessariamente por dificuldades de ordem jurídica. $\mathrm{O}$ entendimento aqui proposto é de que a ética é um dos aspectos que estão no cerne dos grandes conflitos atuais. Faz-se necessário repensar os modelos éticos na busca de uma moralidade que seja congruente com o panorama social contemporâneo.

Nesse sentido, a proposta de modelo ético de Hans Jonas, fundamentada na responsabilidade das decisões do homem como uma forma de auxiliar o sistema de justiça na busca de sua eficácia, assim como a perspectiva da sociedade não necessitar tão frequentemente desse sistema, uma vez que atitudes seriam tomadas com base em pressupostos que tenderiam a diminuir a judicialização da vida.

Pois, como apontado por Fukuyama (2003, 134-137), apesar da não existência de definições simples para a natureza humana em direitos humanos, a discussão passa necessariamente pela filosofia, no que se refere à reflexão sobre os fins humanos. Tal análise permite não um consenso coletivo, mas minimamente o início do estabelecimento de hierarquia de direitos, onde se passa a excluir soluções para as questões de direitos que anteriormente podem ter sido poderosas. Dessa forma, não se pode falar de direitos humanos e consequentemente sobre justiça, política e moralidade sem o fundamento do que realmente são os seres humanos enquanto espécie. Abre-se, portanto a possibilidade de intersecções importantes entre a filosofia e o sistema de justiça.

Assim, a ideia de justiça na contemporaneidade deve ser amplificada, pois se antes, como afirma Jonas (2006, p. 44) o imperativo é que se fizesse justiça de qualquer forma, mesmo à custa do perecimento inclusive da natureza, até porque se acreditava na sua "eterna" renovação, atualmente a situação real da escassez e extinção de determinados recursos é fato, em função das ações humanas, justas ou não. Para a tentativa de garantia da vida humana e de sua dignidade, surgem então cada vez mais leis, na busca da justiça teleológica, como afirma Jonas (2006, p. 44): "questões que nunca foram antes objeto de legislação, ingressam no circuito das leis que a "cidade" global tem de formular, para que possa existir um mundo para as próximas gerações de homens".

Essa perspectiva relaciona-se mais com as políticas públicas do que com ações privadas, pois estas têm um intervalo menor de tempo de ação e responsabilidade do que aquelas, que se estendem para períodos mais longos. Portanto, exigem-se novos limites para novos tempos e assim o Estado deveria considerar a perspectiva de ética apresentada por Hans Jonas, para que políticas sejam implementadas visando não somente a garantia de direitos atuais, mas do futuro da humanidade.

Se por um lado, esse fato parece exigir mais leis e mais controle das mesmas, o que sobrecarregaria ainda mais o Pode Judiciário, por outro lado, o respeito aos direitos é o primeiro passo para diminuição de conflitos instaurados em todas as modalidades de relações sejam privadas ou institucionais. Certamente tal situação não é 
só da responsabilidade do campo da política, pois como afirma Jonas (2006, p. 64) "antes de se perguntar sobre que poderes representariam ou influenciariam o futuro, devemos nos perguntar sobre qual perspectiva ou qual conhecimento valorativo deve representar o futuro no presente".

O que parece estar em jogo é a questão: que valores devem nortear nossas ações, sejam privadas ou coletivas, e qual a sua implicação sobre os indivíduos que são nossos contemporâneos, mas também sobre os que estão por vir? No campo jurídico recentemente se tem discutido sobre o modelo de justiça restaurativa como mais apropriado à resolução de determinados conflitos. Essa proposta implica em maior participação, promoção de empatia e responsabilização das ações pelas partes envolvidas. A pretensão é o incentivo da cultura da paz, ao invés da cultura adversarial, o que pode guardar algumas aproximações com o princípio da responsabilidade.

Entende-se aqui, que a proposta de Hans Jonas, embora não aborde diretamente aspectos funcionais ao sistema de justiça, indiretamente, ao inserir temáticas de políticas públicas responsáveis para o bem-estar atual e futuro da humanidade, volta-se a assegurar a dignidade humana e, nesse sentido, abre-se à minimização dos conflitos e à solução por outros fundamentos éticos assentados na responsabilidade. Além disso, se for inserida mais amplamente no meio acadêmico e profissional, a discussão sobre o modelo ético do princípio da responsabilidade, os sujeitos estarão mais implicados em suas decisões, sejam da esfera pública ou privada, o que pressupõe a promoção de justiça mais participativa dos cidadãos. Passaria então a ser implementada uma ideia de justiça socializada e prospectiva e que é mais concernente à configuração subjetiva e sociológica contemporânea.

\section{CONSIDERAÇÕES FINAIS}

A pós-modernidade trouxe inúmeros benefícios para a humanidade. Certamente alguns sofrimentos foram dirimidos, assim como os avanços tecnológicos permitiram que o ser humano tivesse facilitada uma serie de tarefas pessoais e coletivas, sejam de lazer, relativas a necessidades básicas ou de trabalho. No entanto, vive-se nas últimas décadas com o grande desafio de algo muito básico e, pode-se dizer quase nada "tecnológico": a natural sobrevivência humana.

Parece que se ultrapassaram os limites de até onde era viável chegar, em termos de progresso da civilização, sem danificar os pressupostos naturais e sociais da vivência do homem. Então está se falando de limites, de normas, de agentes regularizadores, de leis...

Para a sociedade, esse fato está relacionado ao funcionamento de seu sistema legal, que tem permitido essas ultrapassagens perversas, pois ao prometer "melhor qualidade de vida" mediante o consumo de tecnologia, não se coloca no "rótulo" que o ato de consumir será por tempo determinado, escasso e breve, se não forem promovidas mudanças nos dispositivos permissivos de tais ocorrências. 
A realidade tal como se apresenta, em função das violências reais e subliminares provocadas pelo processo civilizatório, tem se confrontado com crescente número e complexidade de conflitos de diversas ordens que buscam no sistema de justiça a "solução" para direitos que são violados. Assim, o sistema de justiça se embate com demandas múltiplas que nem sempre podem ser atendidas pelo Poder Judiciário.

Talvez, valha a pena procurar alternativas também em outros campos, que não somente o jurídico. E aí se apresenta a ética de Hans Jonas, onde a responsabilidade é o eixo central, como uma possibilidade de trazer fundamentos para as instituições educacionais, políticas, jurídicas, dentre outras, na intenção de promover a aprendizagem e a implementação de um sistema de se fazer justiça voltado para os grandes desafios que a pósmodernidade desencadeou.

\title{
ETHICS OF RESPONSIBILITY: CONTRIBUTION OF HANS JONAS' PROPOSAL FOR EFFECTIVENESS IN THE JUSTICE SYSTEM
}

\begin{abstract}
The postmodern view of the individual as producer-consumer displaces the typically human needs, often essential to their dignity and survival. People and things become means to achieve individual and collective goals focused mainly on hedonism. This fact can lead the man to harmful behavior to another current human being and also to future generations, setting up, therefore, a scenario that requires discussions about the responsibility of human actions, including actions under legal point of view. The concept of legal responsibility has traditionally been linked to imputation idea; and the functioning of the judiciary system depends on the separate identification of individuals (plaintiff and defendant) involved in the damage, as well as the exact recognition of it, its length, and measurement of losses for purposes of penalty enforcement and indemnity calculation. However, the challenges' nature that has been imposing on society in general and, more specifically, the required performance of the State impose new preventive mechanisms, as well as a more effective punishment that makes the justice more efficient. The principle of Jonas' responsibility induces ways to overcome these challenges leading to a justice conception that is able to identify, face, justify, and prevent damages at the present time.
\end{abstract}

Keywords: justice; justice system; effectiveness; responsibility principle; ethics.

\section{REFERÊNCIAS BIBLIOGRÁFICAS}

ALENCASTRO, Mario Sergio Cunha; HEEMANN, Ademar. Hans Jonas: as bases filosóficas para uma ética da sustentabilidade. $\mathrm{s} / \mathrm{d}$.

Disponível em: http://www.unifae.br/publicacoes/pdf/sustentabilidade/mario_ademar_hansjonas.pdf Acesso em $28 / 07 / 2013$

BARBOSA, Claudia Maria. (coord.) Projeto Conjunto de Cooperação de Pesquisa: Limites e possibilidades da eficácia da prestação jurisdicional no Brasil. Diretoria de Programas e Bolsas no País - Coordenação-Geral de 
Proagramas Estratégicos- Coordenação de Indução e Inovação. Edital No 020/2010/CAPES/CNJ Reflexões para um judiciário socioambientalmente responsável. Revista da Faculdade de Direito da UFPR v. 48, p. 107-121, 2008, Curitiba, Paraná.

Reflexiones sobre un sistema judicial eficaz en una sociedad socioambientalmente responsable. El Otro Derecho, v. 39, p. 67-85, 2010.

BARROS, Mayra Rafaela Closs Bragotto. A heurística do medo e a responsabilidade não-recíproca na teoria ética de Hans Jonas. Revista Poros v.4/n.7 (2012), ISSN 2175-1455. Disponível em http://200.233.146.122:81/revistadigital/index.php/poros/article/viewPDFInterstitial/381/417. Acesso em $20 / 07 / 2013$

BATTESTIN, Cláudia; GHIGGI, Gomercindo. O princípio responsabilidade de Hans Jonas: um princípio ético para os novos tempos. Rev.Thaumazein, Ano III, número 06, Santa Maria (Outubro de 2010), pp. 69-85. Disponível em http://sites.unifra.br/Portals/1/ARTIGOS/numero_06/battestin_5.pdf. Acesso 23/07/2013

BAUMANN, Zygmunt. O mal-estar da pós-modernidade. 1ª.Ed.Rio de janeiro: Jorge Zahar Editor, 1998. 272 p Vida Líquida. 2a Ed.Rio de Janeiro: Jorge Zahar Editor, 2009.210 p.

BECK, Ulrich. Sociedade de risco: rumo a uma outra modernidade. 2. ed. São Paulo: Editora 34, 2011.383 p.

BRITO, Leila Maria Torraca de. O sujeito pós-moderno e suas demandas judiciais. Revista Psicologia: Ciência e Profissão, vol 32, no. 3. Brasilia, 2012.

CARVALHO, Maria Cristina Neiva de; CANDIOTTO, Kleber Bez Birollo. Contribuições das ciências cognitivas para o estudo da construção do conceito de justiça. Revista Psicologia Argumento. p.529-536, 2013 jul. /set. 31(73)

MEGUER, Maria de Fátima Batista; FREITAS, Cinthia O. de A 'Justiça' como objeto de consumo: é

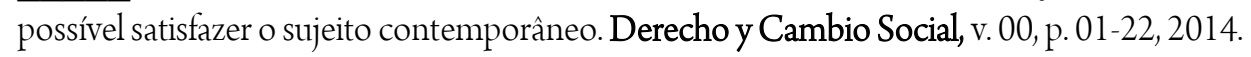

BRASIL. Código Civil (2002). Código civil brasileiro e legislação correlata. 2. ed. Brasília: Senado Federal, Subsecretaria de Edições Técnicas, 2008.616 p.

DUFOUR, Dany-Robert. O divino mercado - a revolução cultural liberal. $1^{\text {a }}$ Ed.Rio de Janeiro: Companhia de Freud, 2008.285 p.

FUKUYAMA, Francis. Nosso futuro pós-humano - consequências da revolução da biotecnologia. $1^{\text {a }}$ Ed. Rio de Janeiro: Rocco, 2003.268 p.

GLÜCK, Mario. El principio de responsabilidad: ¿una etica impracticable? Reflexiones en torno a la Propuesta política de Hans Jonas. Revista e Filosofia, V. 18, No22, p. 37-55, jan. /jun. 2006

JONAS, Hans. O princípio responsabilidade - ensaio de uma ética para a civilização tecnológica. Rio de Janeiro: Contraponto - Ed PUC - Rio, 2006, p. 354 p.

KYMLICKA, Will. Filosofia Contemporânea. São Paulo: Martins Fontes, 2006. 409 p.

LA TAILLE, Yves de. Para um estudo psicológico das virtudes morais. Rev. Educação e Pesquisa, São Paulo, v.26, n.2, p.109-121, jul. /dez. 2000 
LEBRUN, Jean-Pierre. Um mundo sem limite - ensaio para uma clínica psicanalítica do social. $1^{\text {a }}$ Ed.Rio de Janeiro: Companhia de Freud, 2004.218 p.

MOMO, Giovani, A “inexistência” do sujeito de direitos em Hans Jonas. Filosofazer. Passo Fundo, n. 36, jan. /jun. 2010. 135. Disponível em http://201.86.212.89/seer/index.php/filosofazer/article/view/129/152 Acesso em $20 / 07 / 2013$

NAVAS, Antonio Linde. La educación moral según Lawrence Kohlberg: Uma utopía realizable. Praxis Filosófica Nueva serie, No. 28, p.7-22, Enero-Junio 2009

OLIVEIRA, Jelson Roberto de. Por que uma ética do futuro precisa de uma fundamentação ontológica segundo Hans Jonas. Rev. Filos. Aurora, Curitiba, v. 24, n. 35, p. 387-416, jul. / dez. 2012

SANDEL, Michael J. Justiça- O que é fazer a coisa certa. 4ª. Ed. Rio de Janeiro: Civilizações Brasileira, 2011.349 p.

SANTOS, Robinson dos. O problema da técnica e a crítica à tradição na ética de Hans Jonas. In: Robinson dos Santos, Jelson Oliveira, Lourenço Zancanaro (orgs). Ética para a civilização tecnológica: em diálogo com Hans Jonas. São Paulo: Centro Universitário São Camilo, 2011.P. 21-40

SEN, A. A ideia de justiça. São Paulo: Companhia das Letras, 2011.492 p.

KLIKSBERG, Bernardo. As pessoas em primeiro lugar - a ética do desenvolvimento e os problemas do mundo globalizado. São Paulo: Companhia das Letras, 2010.404 p.

SGANZERLA, Anor. Biologização do ser moral em Hans Jonas. Rev. Filosofia Aurora, Curitiba, v. 25, n. 36, p. 155-178, jan. /jun. 2013. Disponível em http://www2.pucpr.br/reol/index.php/RF?ddl=7769\&dd99=pdf Acesso em 25/07/2013

TAVARES NETO, José Querino; BARBOSA, Claudia Maria.. Democratização da jurisdição constitucional: uma análise a partir de Pierre Bourdieu. Revista da Faculdade de Direito da UFG, v. 36, p. 60-84, 2012.

WALDMANN, Ricardo Libel; ELIAS, Luiz Augusto da Veiga. Responsabilidade e Antecipação: o regramento da inovação na civilização tecnológica. Revista de Direito Ambiental, vol.17, no. 67, p. 71-86, jul/set 2012.

SITES CONSULTADOS:

http://www.planalto.gov.br/ccivil_03/_Ato2011-2014/2014/Lei/L13010.htm

Trabalho enviado em 08 de setembro de 2015.

Aceito em 07 de outubro de 2015. 